\title{
Временные установки современных мужчин и женщин
}

\section{Ирина А. Ральникова*, Яна К. Смирнова}

Алтайский государственный университет, г. Барнаул, Российская Федерация

*E-mail: irinaralnikova@yandex.ru

\begin{abstract}
Аннотация
Ввеление. В статье рассмотрены предикторы временных установок мужчин иженщин в возрасте от 25 Ао 45 ^ет. На теоретическом уровне становление проблемы времени в психологической науке проанализировано в контексте классического, неклассического и постнеклассического илеалов рациональности. Осмыслена категория времени в психологии с позиций постнеклассики, которая решает противостояние объективного и субъективного, предполагая, что во взаимодействии субъекта с объектом время рождается как качественно новая реальность, не сводимая ни к субъективному, ни к объективному.
\end{abstract}

Методы. В качестве методов сбора научной информации выступили метоА опроса и метод тестов; математико-статистическими методами стали расчет Т-критерия Стьюлента Аля независимых выборок и регрессионный анализ с применением метода пошагового отбора.

Результаты. Посредством применения трансспективного анализа к проблеме времени в психологии зафиксировано основное содержание становления временной проблематики на к^ассическом, неклассическом, постнеклассическом этапах. Выявлены временные установки мужчин и женщин. Определены предикторы временных установок в контексте половых различий.

Обсужаение результатов. Впервые выявлены различия временных установок мужчин и женщин в контексте определения преАикторов, их обусловливающих. Оригинальными являются научные результаты о наличии и характере зависимости временных установок и параметров Аичностно-субъектного фрункционирования, в частности самоактуализации, психологического благополучия, копинг-стратегий, психологических защит. Показано, что не столько отАельные ценности как таковые, сколько полсистемы ценностей, приналлежащих к различным сорерам жизни (семьи, увлечений, профрессиональной Аеятельности, быта и т. А.) участвуют в фрормировании временных установок мужчин и женщин. Ценности определяют специфику регуляции времени жизни женщин и мужчин. Выявлены различия мужчин и женщин в отношении характера взаимосвязи ценностных выборов и фиксированности установки временной перспективы. Аоказана важная роль копинг-стратегий в Аичностной организации времени. 


\section{КАючевые слова}

неклассический илеал рациональности, постнеклассический илеал рациональности, временные установки, ценностные предпочтения, психологические защиты, копинг-стратегии, психологическое благополучие, самоактуализация, молоАость, взрослость

\section{Основные положения}

- определены ценностные основания временных установок современных мужчин и женщин;

- показано, что разный набор ценностей ^ежит в основе оценки временных этапов жизни (прошлого, настоящего и булущего);

Аоказана приоритетная роль копинг-стратегий в ^ичностной организации времени наряду с функционированием психологических защит, самоактуализацией, психологическим благополучием.

\section{Для цитирования}

Ральникова И. А., Смирнова Я. К. Временные установки современных мужчин и женщин // Российский психологический журнал. 2018. Т. 15, № 4. С. 54-69. DOI: 10.21702/ rpj.2018.4.3

Материалы статьи получены 05.03.2018

UDC 159.99

DOI: $10.21702 /$ rpj.2018.4.3

\section{Time Attitudes in Contemporary Men and Women}

\section{Irina A. Ralnikova*, Yana K. Smirnova}

Altai State University, Barnaul, Russian Federation

*Corresponding author. E-mail: irinaralnikova@yandex.ru

\section{Abstract}

Introduction. This paper investigates predictors of time attitudes in men and women aged 25-45 years. A theoretical analysis concentrates on the concept of time in the context of classical, non-classical, and post-non-classical ideals of rationality. In the process of individuals' interaction with objects, time is born as a qualitatively new reality that is reducible neither to the subjective nor to the objective perspective. The psychological category of time is interpreted within the framework of post-non-classical approach that is capable of solving that contradiction.

Methods. The survey method was employed in the study for data collection. Mathematical and statistical analyses included Student's t-test for independent samples and step-wise regression analysis. 
ОБЩАЯ пСИхолОГИЯ

Results. The transspective analysis of the problem of time in psychology enabled authors to describe its dynamics at classical, non-classical, and post-non-classical stages. The study examined time attitudes in men and women and determined their predictors in the context of gender differences.

Discussion. This is the first study that examines the predictors of time attitudes in men and women. Its original findings suggest that there is a dependency between time attitudes and parameters of personal and subjective functioning, including self-actualization, psychological well-being, coping strategies, and psychological defenses. Not so much certain values, as the subsystems of values belonging to various aspects of life (family, hobby, profession, household, etc.) participate in the formation process of time attitudes in men and women. Personal values determine the specific character of regulation of the time of life in women and men. Coping strategies are important for personal organization of time. The study showed the differences in interrelationships between value choices and time attitudes in men and women.

\section{Keywords}

non-classical ideal of rationality, post-non-classical ideal of rationality, time attitudes, value preferences, psychological defenses, coping strategies, psychological well-being, self-actualization, youth, adulthood

\section{Highlights}

- The study examined value foundations of time attitudes in contemporary men and women.

Different sets of values determine the evaluation of time periods of life (the past, the present and the future).

- Along with psychological defenses, self-actualization, and psychological well-being, coping strategies play a major role in the personal organization of time.

\section{For citation}

Ralnikova I. A., Smirnova Ya. K. Time Attitudes in Contemporary Men and Women. Rossiiskii psikhologicheskii zhurnal - Russian Psychological Journal, 2018, V. 15, no. 4, pp. 54-69 (in Russian). DOI: 10.21702/rpj.2018.4.3

Original manuscript received 05.03.2018

\section{Введение}

Возрастание темпов жизни, ускорение общественных преобразований, увеличение степени экстремальности и неопределенности современных условий существования человека задают новую актуальность изучения проблемы времени в психологии. Судьба человека во многом зависит от его 


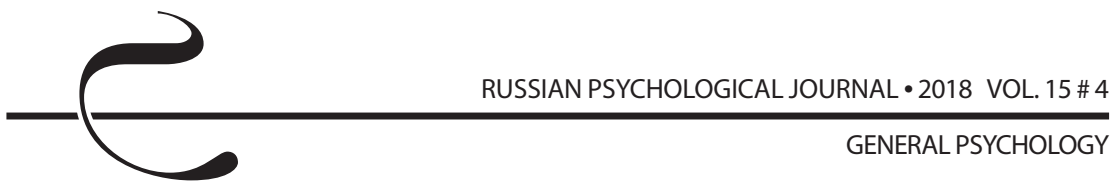

временной установки [1, 2]. Сегодня психология ставит вопросы и ищет ответы относительно закономерностей трансформаций развертывания жизненного пути человека [3, 4, 5, 6, 7, 8], особенностей осмысления им событий прошлого, восприятия актуального отрезка времени, представлений о будущем $[9,10$, $11,12,13,14]$. Современные условия бытия достраиваются дополнительными требованиями общества к человеку, связанными с активностью жизненного выбора, проектированием личных достижений, управлением временем собственной жизни $[15,16,17,18,19]$. Вместе с этим, не на все вопросы в лоне данной проблематики есть окончательные ответы. Недостаточно изученной остается проблема опосредованности характера временных установок человека особенностями его личностного функционирования.

Опираясь на научные взгляды В. Е. Клочко [20, 21], мы определяем статус временных установок как той новой реальности, возникающей во взаимодействии среды и субъекта, имеющей принципиальные отличия от субъективного и от объективного, и не сводимой ни к одному, ни к другому. На основе данных научных размышлений рождается идея о том, что временные установки человека в современном мире обусловлены характером «встречи» объективного и субъективного в сознании человека. В свою очередь, такая «встреча» объективирует себя в индивидуально-личностных, эмоциональных, ценностно-смысловых, мотивационных особенностях, поведенческих проявлениях человека.

\section{Цель}

В статье представлены результаты исследования предикторов временных установок мужчин и женщин. Показана содержательная специфика обусловленности данных установок системой личностных ценностей в зависимости от половой принадлежности. Временные установки изучены в контексте их взаимосвязи с самоактуализацией, психологическим благополучием, способами копинга, психологическими защитами.

\section{Методы}

С целью определения временных установок применялся «Опросник временной перспективы» (Ф. Зимбардо) в адаптации А. Сырцовой, Е. Т. Соколовой, О. В. Митиной [22]. Для выявления мотивационно-ценностной структуры личности использовался «Морфологический тест жизненных ценностей» (В. Ф. Сопов, Л. В. Карпушина) [23]. В целях диагностики механизмов психологической защиты Я применялся опросник «Индекс жизненного стиля» (Р. Плутчик, Г. Келлерман) [24]. Способы преодоления трудностей в различных сферах психической деятельности выявлялись посредством «Опросника по выявлению способов копинга» (Р. Лазарус, С. Фолкман) в адаптации Т. Л. Крюковой, 
Е. В. Куфтяк [25]. Актуальное психологическое благополучие диагностировалось с помощью «Шкалы психологического благополучия» (К. Рифф) [26]. С целью определения степени самоактуализации личности использовался самоактуализационный тест (Л. Я. Гозман, М. В. Кроз, М. В. Латинская) [27].

Методы математико-статистической обработки данных представлены процедурами расчета Т-критерия Стьюдента для независимых выборок, регрессионным анализом, выполненными с помощью компьютерного статистического пакета «SPSS» 22.0.

В эмпирическом исследовании приняли участие 108 человек в возрасте от 25 до 45 лет, из них 39 мужчин и 69 женщин.

\section{Результаты}

\section{Категория времени в психологии}

Время представляет собой фундаментальную характеристику человеческого бытия. В понимании И. Канта восприятие и мышление о мире формируются и управляются именно субъективным чувством времени. В современных философских работах содержится идея о том, что время определяет специфику субъективности, задает проблему смысла [28].

Изучение проблемы времени получило широкое распространение в отечественной и зарубежной психологии (Б. Г. Ананьев [29], С. Л. Рубинштейн [30], К. А. Абульханова-Славская [1], В. И. Ковалев [31], Е. И. Головаха и А. А. Кроник [32], N. Fieulaine [6], J. McGrath [5], T. Milfont [17] и др.). На современном этапе развития психологической науки временная проблематика осмыслена с разных сторон. Становление временной проблематики в психологии можно отследить на этапах ее развития, которые принято обозначать как классический, неклассический, постнеклассический [33].

Время в качестве фактора человеческой психики стало рассматриваться в классический период психологической науки. В данную эпоху осмысление временной проблематики основывалось на идее постижения объективных законов природы [34]. В данной логике был обозначен масштаб исследования психологического времени - ситуативный, когда научный интерес направлен на изучение непосредственного восприятия человеком коротких временных интервалов, несоизмеримых со временем жизни человека. Вместе с этим было выявлено наличие субъективной составляющей переживания времени, которая стала предметом исследования на неклассическом этапе развития психологии. Классический этап развития осмысления категории времени психологией науки доказал, что психологическое время имеет место быть наряду с физическим временем. Смена идеалов рациональности классического на неклассический подготовила условия научного исследования субъективного, психологического, внутреннего времени человека [35]. 
Неклассическая парадигма фокусировалась на субъективности наблюдателя и роли субъективности в конструировании картины жизни. В период неклассического этапа развития науки формируется биографический масштаб осмысления категории времени, предполагающий изучение времени жизни человека от рождения до смерти [20].

Неклассическая парадигма представлена научными идеями в отношении субъективного времени человека (Б. Г. Ананьев [12], С. Л. Рубинштейн [13], В. И. Ковалев [31] и др.). На данном этапе психологическая наука делает важный шаг в направлении необходимости интеграции объективных временных требований и субъективных процессов переживания времени в качестве внутренних условий его организации [20]. Неклассический идеал рациональности также определяет важный аспект познания времени человека, связанный с его ценностно-смысловой обусловленностью, которая занимает здесь центральное место [36]. К. А. Абульханова-Славская и В. И. Ковалев подчеркивают невозможность осмысления переживания времени человеком изолированно от ценностей и личностных смыслов [1, 31]. Определив границы исследования времени в психологии, его детерминанты, динамику, факторы саморегуляции, обусловленность ценностно-смысловыми переменными, эпоха неклассической науки не смогла до конца преодолеть дихотомию субъективного и объективного [20, 35]. Решение данной проблемы, по мнению В. Е. Клочко, возможно в эпоху становления постнеклассического мышления, которое способно разрешить это противостояние [20]. Попадая в «зону перекрытия парадигм» (В. Е. Клочко), проблема времени получила сегодня возможность ее осмысления с позиций системного подхода. Не претендуя на окончательный вариант трактовки времени, мы, опираясь на основные положения антропологической психологии [21], сформулировали рабочее определение времени как новообразования, порождаемого системой «человек». Время предстает перед человеком как качественно новая сверхчувственная реальность, возникающая в ответ на «встречу» объективного и субъективного.

\section{Результаты эмпирического исследования временных установок мужчин и женщин}

На основе анализа описательных статистик, полученных по результатам диагностики временной перспективы, мы можем охарактеризовать временные установки мужчин и женщин.

У мужчин преобладает выраженность установки на позитивное прошлое $(3,67 \pm 0,61)$ и на будущее $(3,59 \pm 0,62)$. Незначительно ниже у мужчин выражена установка на гедонистическое настоящее $(3,03 \pm 0,55)$. Наименьшую выраженность у мужчин имеет установка фаталистическое настоящее $(2,47 \pm 0,65)$ и негативное прошлое $(2,45 \pm 0,79)$. 
На выборке женщин обнаружена похожая тенденция. Как и у мужчин, у женщин преобладает выраженность установки на позитивное прошлое $(3,59 \pm 0,65)$ и на будущее $(3,66 \pm 0,55)$, гедонистическое настоящее $(3 \pm 0,57)$. Наименьшую выраженность у женщин также имеет установка на фаталистическое настоящее $(2,63 \pm 0,64)$ и негативное прошлое $(2,51 \pm 0,66)$.

Мужчины и женщины характеризуются близкими временными установками, среди которых доминируют временные установки на позитивное прошлое и будущее. Такие временные предпочтения свидетельствуют о принятии респондентами собственного прошлого, при котором «встреча» с различными жизненными событиями, как позитивными, так и негативными осмысливается с позиций извлечения опыта, способствующего развитию личности. Временная установка на будущее свидетельствует о целенаправленности жизни исследуемых мужчин и женщин, важности для них планировать свое будущее, ставить цели. Вместе с этим респонденты склонны воспринимать свою жизнь как последовательную смену временных этапов - от прошлого к настоящему и будущему. Несмотря на близость временных установок в группах мужчин и женщин, предикторы таких установок продемонстрировали существенные различия.

\section{Предикторы временных установок женщин}

При помощи регрессионного анализа было выявлено, что на выборке женщин временная установка на будущее будет зависеть $\left(R^{2}=0,616, p=0,001\right)$ от выраженности: поиска социальной поддержки $(\beta=-0,605, p=0,0001)$, защитного механизма компенсации ( $\beta=-0,299, p=0,037)$, принятия ответственности $(\beta=0,488, p=0,003)$, планирования решения проблемы $(\beta=0,304, p=0,027)$.

Временная установка на негативное прошлое будет зависеть $\left(R^{2}=0,727\right.$, $p=0,0001)$ от выраженности: ориентации во времени $(\beta=-0438, p=0,001)$, ценности развития себя в сфере увлечения $(\beta=-0,536, p=0,0001)$, ценности собственного престижа в сфере образования $(\beta=0,268, p=0,028)$, защитного механизма реактивного образования $(\beta=0,371, p=0,003)$.

Далее было выявлено, что у женщин временная установка на гедонистическое настоящее $\left(R^{2}=0,855, p=0,0001\right)$ зависит от выраженности: конфронтационного копинга $(\beta=0,461, p=0,0001)$, интеллектуализации $(\beta=-0,496$, $p=0,0001)$, ценности собственного престижа в сфере образования $(\beta=0,396$, $p=0,004)$, ценности духовного удовлетворения в образовании $(\beta=0,510$, $p=0,0001)$, материального положения в общественной сфере $(\beta=-0,301$, $p=0,015)$, достижений в сфере увлечений $(\beta=0,261, p=0,018)$, материального положения в физической сфере ( $\beta=-0,244, p=0,047)$.

Временная установка на позитивное прошлое у женщин будет зависеть $\left(R^{2}=0,900, p=0,0001\right)$ от выраженности: ценности развития себя в сфере 
увлечений $(\beta=0,397, p=0,0001)$, личностного роста $(\beta=0,396, p=0,0001)$, принятия ответственности $(\beta=0,440, p=0,0001)$, достижений в сфере увлечений $(\beta=-0,650, p=0,0001)$, ценности сохранения индивидуальности в образовании $(\beta=0,468, p=0,0001)$, самоуважения $(\beta=0,465, p=0,016)$, цели в жизни $(\beta=0,767, p=0,027)$.

Установка на фаталистическое настоящее зависит $\left(R^{2}=0,866, p=0,0001\right)$ от выраженности: автономии ( $\beta=-0,360, p=0,001)$, защитного механизма проекции $(\beta=0,327, p=0,001)$, ценности духовного удовлетворения в образовании ( $\beta=-0,336, p=0,001)$, синергии $(\beta=-0,301, p=0,002)$, социальных контактов в физической сфере $(\beta=0,283, p=0,004)$, сохранения индивидуальности в общественной сфере $(\beta=-0,200, p=0,042)$.

\section{Предикторы временных установок мужчин}

На выборке мужчин выявилась иная тенденция. При помощи регрессионного анализ было обнаружено, что временная установка на будущее у мужчин будет зависеть $\left(R^{2}=1, p=0,0001\right)$ от выраженности: планирования решения проблемы ( $\beta=1,6139, p=0,0001)$, духовного удовлетворения в физической сфере $(\beta=-0,631, p=0,0001)$, достижений в сфере увлечений $(\beta=0,304$, $p=0,0001)$, креативности в общественной сфере $(\beta=-0,195, p=0,0001)$, материального положения в общественной сфере $(\beta=-0,180, p=0,0001)$, защитного механизма вытеснения $(\beta=-0,076, p=0,003)$.

Временная установка на негативное прошлое будет зависеть $\left(R^{2}=1\right.$, $p=0,0001)$ от: креативности в семейной сфере $(\beta=0,569, p=0,0001)$, социальных контактов в сфере образования $(\beta=0,871, p=0,0001)$, развития себя в сфере увлечений $(\beta=0,029, p=0,001)$, ориентированности на самопринятие $(\beta=0,446, p=0,0001)$, достижения в профессиональной сфере $(\beta=-0,965$, $p=0,0001)$, ценности креативности в сфере увлечений $(\beta=-0,286, p=0,0001)$, актуализации защитного механизма замещения $(\beta=-0,166, p=0,0001)$, личностного роста $(\beta=-0,106, p=0,0001)$.

На мужской выборке временная установка на гедонистическое настоящее $\left(R^{2}=0,994, p=0,0001\right)$ зависит от выраженности: ценности достижений в сфере увлечений $(\beta=1,183, p=0,0001)$, поддержки $(\beta=0,316, p=0,0001)$, актуализации защитного механизма компенсации $(\beta=-0,588, p=0,0001)$.

Временная установка на позитивное прошлое у мужчин будет зависеть $\left(R^{2}=0,784, p=0,007\right)$ от выраженности положительных отношений с другими $(\beta=0,784, p=0,007)$.

Установка на фаталистическое настоящее зависит $\left(R^{2}=1, p=0,0001\right)$ от: выраженности спонтанности ( $\beta=-0,360, p=0,001)$, принятия ответственности $(\beta=-0,244, p=0,001)$, ценности материального положения в сфере семьи $(\beta=0,384, p=0,001)$, защитного механизма «реактивное 
образование» $(\beta=0,242, p=0,001)$, собственного престижа в сфере увлечений $(\beta=-0,217, p=0,002)$, самоконтроля $(\beta=-0,075, p=0,003)$, ценности сохранения индивидуальности в сфере семьи $(\beta=0,029, p=0,007)$, ценности социальных контактов в профессиональной сфере $(\beta=0,010, p=0,029)$.

\section{Обсуждение результатов}

Полученные результаты показывают, что у женщин на фиксированность временных установок большее влияние оказывают такие ценности, как: ценности развития себя, ценности собственного престижа, сохранения индивидуальности и духовного удовлетворения. У мужчин на фиксированность временных установок чаще оказывают влияние ценности социальных контактов, материального положения, креативности и достижений.

При этом временную установку будущего у женщин ценности не определяют, и будущее связано с принятием ответственности и планированием решения проблем как копингом. Однако у мужчин временная установка на будущее определяется ценностями достижения, материального благополучия и снижением ценностей духовного удовлетворения и креативности.

Важно, что наблюдается неравнозначное ценностное влияние на временную установку. Например, у женщин ценности социальных контактов обуславливают установку на фаталистическое настоящее, а ценности духовного удовлетворения и сохранения индивидуальности ее снижают. У мужчин именно ценности материального положения, сохранения индивидуальности, социальных контактов повышают установку на фаталистическое настоящее.

Видно, что и у мужчин, и женщин ценности напрямую участвуют в формировании представления о своем психологическом времени. Ценности оказывают влияние на временную установку личности, определяя особенности женщин и мужчин в регуляции времени жизни.

При этом если временная перспектива может быть осмыслена как выражение собственной системы личностных ценностей и смыслов, которая позволяет создать согласованную или дисбалансированную систему координат для жизни, то важно учитывать не просто приоритет ценностей, а определение сферы реализации этих ценностей. Так, у женщин на временную установку чаще влияют ценности, определенные в сфере увлечений и образования, т. е. ценности, связанные с личностным ростом. У мужчин - это чаще ценности сфер семьи, увлечений и профессиональной деятельности. Полученные различия отображают, что именно ценностная «насыщенность» сферы жизнедеятельности определяет специфику переживания временной перспективы.

Исследование временных установок современных мужчин и женщин позволило подтвердить известный в психологической науке факт ценностно-смысловой обусловленности представлений человека о времени своей жизни. 
Именно ценности как категории, размещенные во временной перспективе, помогают упорядочить нашу жизнь, структурировать ее и придать ей смысл. Ценности объективируют себя во временных установках, задавая «призму» анализа событий прошедшего, настоящего и грядущего отрезков жизни, а также из взаимозависимости. Осмысление человека в качестве психологической системы позволяет рассмотреть ценностные предпочтения как основание построения целостной картины времени жизни человеком. Вместе с этим, важно отметить, что значительную роль играет не только иерархия ценностных ориентаций, но и учет изменения данной иерархии в различных сферах жизнедеятельности. Выявлено, что существует специфика данного влияния у женщин и мужчин, что уточняет специфику переживания временных интервалов жизненного пути в зависимости от пола.

Выявлено, что ценностная обусловленность психологического времени имеет половые различия, а именно: взаимосвязь ценностных выборов и фиксированности установки временной перспективы у мужчин и женщин отлична.

Эмпирические данные убедительно демонстрируют ведущую роль стратегий преодоления трудностей в личностной организации времени. Полученные результаты доказали, что разные временные установки будут не одинаково фиксироваться - в зависимости от различий в эффективных либо неэффективных способах преодоления трудностей в различных сферах психической деятельности и оценки собственных ресурсов. Фиксация переживания на разных временных установках зависит от когнитивных, эмоциональных и поведенческих стратегий, которые используются в совладании со стрессом мужчины и женщины. Подтверждается наличие трансформации переживания интервалов времени в зависимости от индивидуального способа восприятия и оценки ситуации жизнедеятельности, а именно от копинг-стратегии как оценки собственных ресурсов совладания с жизненной ситуацией. Выявлено, что проблемно-фокусированные стратегии и эмоционально-фокусированные стратегии по-разному влияют на трансформацию временных установок у мужчин и женщин. На временные установки и у мужчин и у женщин влияют копинги, сфокусированные на проблеме (принятие решений и совершение конкретных действий для преодоления стресса). Именно стратегии способа видения проблемы, изменения проблемы могут способствовать фиксации переживании того или иного временного интервала. При этом влияние на временную установку будущего оказывают именно продуктивные копинги: поиска социальной поддержки, принятия ответственности, у женщин, и планирования решения проблемы у мужчин. 
ОБЩАЯ ПСИХОЛОГИЯ

\section{Благодарности}

Исследование выполнено при поддержке Российского фонда фундаментальных исследований, проект 17-36-00023 - ОГН «Жизненные перспективы человека в изменяющемся мире».

\section{Acknowledgments}

This work was supported by a grant from the Russian Foundation for Basic Research for studying Human Life Prospects in a Changing World.

\section{Литература}

1. Абульханова К. А., Березина Т. Н. Время личности и время жизни. СПб.: Алетейя, 2001. 304 с.

2. Зимбардо Ф., Бойд Дж. Парадокс времени. Новая психология времени, которая улучшит вашу жизнь. СПб.: Речь, 2010. 352 с.

3. Ральникова И. А. Перестройка системы жизненных перспектив человека на этапе переломных событий:монография. Барнаул:Изд-во АлтГУ, 2012. 194 с.

4. Зарубин П. В., Сырцова А. Временная перспектива и экономическая нестабильность: сравнительное исследование 2007 и 2013 гг. // Психологические исследования. 2013. T. 6, № 32. C. 9. URL: http://psystudy.ru/index. php/num/2013v6n32/911-zarubin32.html (дата обращения: 15.11.2018).

5. McGrath J., Tschan F. Temporal Matters in Social Psychology: Examining the Role of Time in the Lives of Groups and Individuals. Washington DC: APA, 2004. 227 p.

6. Fieulaine N. Perspective Temporelle, Situations de Précarité et Santé: Une Approche Psychosociale du Temps. Sciences de l'Homme et Société. Université de Provence - Aix-Marseille I, 2006. 385 p. URL: https://tel.archives-ouvertes. $\mathrm{fr} /$ file/index/docid/408117/filename/These N Fieulaine.pdf (Accessed 02 December 2018).

7. Ralnikova I., Smirnova Y. Life prospects of the unemployed: invariant and variable components in the prism of the last decade (2009-2018) // SHS Web of Conferences. 2018. Vol. 55. DOI: $10.1051 /$ shsconf/20185502028

8. Muzdybayev K. Experience of time in period of crisis // Психологический журнал. 2000. Т. 21, № 4. С. 20-21.

9. Козловская Т. Н. Самоорганизация времени как фактор формирования «образа будущего» студента университета:дисс. ... канд. пед. наук. Оренбург, 2005. 176 с.

10. Сырцова А. Возрастная динамика временной перспективы личности: дисс. ... канд. психол. наук. М., 2008. 317 с.

11. Rohr M. K., John D. T., Fung H. H., \& Lang F. R. A three-component model of future time perspective across adulthood // Psychology and Aging. 2017. Vol. 32 (7). P. 597-607. DOI: 10.1037/pag0000191 
12. Grant S. J. Perspectives in Time: How Consumers Think About the Future // Advances in Consumer Research. 2003. Vol. 30, № 1. P. 143-145.

13. Venaik S., Zhu Y., Brewer P. Looking into the future: Hofstede long term orientation versus GLOBE future orientation // Cross Cultural Management: An International Journal. 2013. Vol. 20, Issue 3. P. 361-385. DOI: $10.1108 /$ CCM-02-2012-0014

14. Ralnikova I., Smirnova Y. Youth personal identity as a factor in the formation of a time perspective // SHS Web of Conferences. 2018. Vol. 55. DOI: $10.1051 /$ shsconf/20185502029

15. Нестик Т. А. Социальная психология времени. М.: Изд-во ИП РАН, 2014. 496 c.

16. Толстых Н. Н. Развитие временной перспективы личности: культурноисторический подход: дисс. ... д-ра психол. наук. М., 2010. 545 с.

17. Milfont T. L., Gouveia V. V. Time perspective and values: An exploratory study of their relations to environmental attitudes // Journal of Environmental Psychology. 2006. Vol. 26, Issue 1. P. 72-82. DOI: 10.1016/j.jenvp.2006.03.001

18. Зимбардо Ф., Сворд Р., Сворд Р. Время как лекарство. СПб.: Питер, 2017. $288 \mathrm{c}$.

19. Ippolitova E., Ralnikova I., Gurova O. Family prospects of the Russian youth in conditions of social change // SHS Web of Conferences. 2018. Vol. 55. DOI: $10.1051 /$ shsconf/20185502002

20. Клочко B. Е. Самоорганизация в психологических системах: проблемы становления ментального пространства личности (введение в трансспективный анализ). Томск: Изд-во Томского государственного университета, 2005. 174 с.

21. Клочко В. Е., Галажинский Э. В. Психология инновационного поведения. Томск: Изд-во Томского государственного университета, 2009. 240 с.

22. Сырцова А., Соколова Е. Т., Митина О. В. Адаптация опросника временной перспективы личности Ф. Зимбардо // Психологический журнал. 2008. Т. 29, № 3. С. 101-109.

23. Сопов В. Ф., Карпушина Л. В. Морфологический тест жизненных ценностей // Прикладная психология. 2001. № 4. С. 9-30.

24. Вассерман Л. И., Ерышев О. Ф., Клубова Е. Б. и др. Психологическая диагностика индекса жизненного стиля. СПб.: Изд-во СПбНИПНИ им. B. М. Бехтерева, 2005. 54 с. URL: http://bekhterev.ru/content/42/2005 dilifestyle.pdf (дата обращения: 02.12.2018).

25. Крюкова Т. Л., Куфтяк Е. В. Опросник способов совладания (адаптация методики WCQ) // Журнал практического психолога. 2007. № 3. С. 93-112.

26. Лепешинский Н. Н. Адаптация опросника «Шкалы психологического благополучия» К. Рифф // Психологический журнал. 2007. № 3. С. 24-37. 
URL: http://media.miu.by/files/store/items/pj/15/pj 152007 3.pdf (дата обращения: 02.12.2018).

27. Гозман Л. Я., Кроз М. В., Латинская М. В. Самоактуализационный тест. М.: Российское педагогическое агентство, $1995.43 \mathrm{C}$.

28. Бороздина Л. В., Спиридонова И. А. Возрастные изменения временной трансспективы субъекта. Сообщение І: Формальные параметры // Психологический журнал. 1998. Т. 19, № 2. С. 40-50.

29. Ананьев Б. Г. Человек как предмет познания. СПб.: Питер, 2001. 288 с.

30. Рубинштейн С. Л. Бытие и сознание. Человек и мир. СПб.: Питер, 2003. 512 c.

31. Ковалев В.И. Особенности субъективной регуляции времени жизни // Время деятельности личности: сб. науч. трудов. Черновцы: Изд-во ЧГУ, 1991. С. 67-75.

32. Головаха Е. И., Кроник А. А. Психологическое время личности. 2-е изд., испр. и доп. М.: Смысл, 2008. 267 с.

33. Гусельцева М. С. Психология и история: смена типов рациональности // Вопросы психологии. 2011. № 2. С. 13-24.

34. Знаков В. В. Психология человеческого бытия - одно из направлений развития психологии субъекта // Психологический журнал. 2008. Т. 29, № 2. С. 69-77.

35. Леонтьев Д. А. Неклассический вектор в современной психологии // Постнеклассическая психология. Социальный конструктивизм и нарративный подход. 2005. № 1 (2). С. 51-71.

36. Cottle T. J. Perceiving time: A Psychological Investigation with Men and Women. N. Y.: John Wiley and Sons Ltd, 1976. 284 p.

\section{References}

1. Abul'khanova K. A., Berezina T. N. Vremya lichnosti i vremya zhizni [Time of personality and life time]. St. Petersburg, Aletheia Publ., 2001. 304 p.

2. Zimbardo P., Boyd J. The time paradox: The new psychology of time that will change your life, New York, NY, Free Press, 2008 (Russ. ed.: Zimbardo F., Boid Dzh. Paradoks vremeni. Novaya psikhologiya vremeni, kotoraya uluchshit vashu zhizn'. St. Petersburg, Rech' Publ., 2010. 352 p.).

3. Ralnikova I. A. Perestroika sistemy zhiznennykh perspektiv cheloveka na etape perelomnykh sobytii [Restructuring of the system of individuals'life prospects at the stage of critical events]. Barnaul, ASU Publ., 2012. 194 p.

4. Zarubin P. V., Syrtsova A. Time perspective and economic instability: A comparative study (2007-2013). Psychological Studies. 2013, V. 6, no. 32, pp. 9 (in Russian). Available at: http://psystudy.ru/index.php/ num/2013v6n32/911-zarubin32.html (Accessed 15 November 2018). 
5. McGrath J., Tschan F. Temporal matters in social psychology: Examining the role of time in the lives of groups and individuals. Washington DC: APA, 2004. $227 \mathrm{p}$.

6. Fieulaine N. Perspective temporelle, situations de précarité et santé: Une approche psychosociale du temps. Sciences de l'Homme et Société. Université de Provence - Aix-Marseille l, 2006. 385 p. URL: https://tel.archives-ouvertes. fr/file/index/docid/408117/filename/These N Fieulaine.pdf (Accessed 02 December 2018).

7. Ralnikova I., Smirnova Y. Life prospects of the unemployed: invariant and variable components in the prism of the last decade (2009-2018). SHS Web of Conferences, 2018, V. 55. DOI: 10.1051/shsconf/20185502028

8. Muzdybayev K. Perezhivanie vremeni v period krizisov [Experience of time in the period of crisis]. Psikholologicheskiy Zhurnal, 2000, V. 21, no. 4, pp. 20-21.

9. Kozlovskaya T. N. Samoorganizatsiya vremeni kak faktor formirovaniya "obraza budushchego" studenta universiteta [Self-organization of time as a factor in the formation of university students' "image of the future"]. Diss. Cand. Sci. (Pedag.). Orenburg, 2005. 176 p.

10. Syrtsova A. Vozrastnaya dinamika vremennoi perspektivy lichnosti [Age-related dynamics of an individual's time perspective]. Diss. Cand. Sci. (Psych.). Moscow, 2008. $317 \mathrm{p}$.

11. Rohr M. K., John D. T., Fung H. H., \& Lang F. R. A three-component model of future time perspective across adulthood. Psychology and Aging, 2017, V. 32 (7), pp. 597-607. DOI: 10.1037/pag0000191

12. Grant S. J. Perspectives in time: How consumers think about the future. Advances in Consumer Research, 2003, V. 30, no. 1, pp. 143-145.

13. Venaik S., Zhu Y., Brewer P. Looking into the future: Hofstede long term orientation versus GLOBE future orientation. Cross Cultural Management: An International Journal, 2013, V. 20, Issue 3, pp. 361-385. DOI: 10.1108/ CCM-02-2012-0014

14. Ralnikova I., Smirnova Y. Youth personal identity as a factor in the formation of a time perspective. SHS Web of Conferences, 2018, V. 55. DOI: $10.1051 /$ shsconf $/ 20185502029$

15. Nestik T. A. Sotsial'naya psikhologiya vremeni [Social psychology of time]. Moscow, Institute of Psychology, RAS Publ., 2014. 496 p.

16. Tolstykh N. N. Razvitie vremennoi perspektivy lichnosti: kul'turno-istoricheskii podkhod [Development of an individual's time perspective: A culturalhistorical approach]. Diss. Dr. Sci. (Psych.). Moscow, 2010. 545 p.

17. Milfont T. L., Gouveia V. V. Time perspective and values: An exploratory study of their relations to environmental attitudes. Journal of Environmental Psychology, 2006, V. 26, Issue 1, pp. 72-82. DOI: 10.1016/j.jenvp.2006.03.001 
18. Zimbardo P. G., Sword R., Sword R. The time cure, 2012 (Russ. ed.: Zimbardo F., Svord R., Svord R. Vremya kak lekarstvo. St. Petersburg, Piter Publ., 2017. 288 p.).

19. Ippolitova E., Ralnikova I., Gurova O. Family prospects of the Russian youth in conditions of social change. SHS Web of Conferences, 2018, V. 55. DOI: $10.1051 /$ shsconf/20185502002

20. Klochko V. E. Samoorganizatsiya v psikhologicheskikh sistemakh: problemy stanovleniya mental'nogo prostranstva lichnosti (vvedenie $v$ transspektivnyi analiz) [Self-organization in psychological systems: Issues of the formation of personal mental space (introduction to the transpective analysis)]. Tomsk, Tomsk State University Publ., 2005. 174 p.

21. Klochko V. E., Galazhinskii E. V. Psikhologiya innovatsionnogo povedeniya [Psychology of innovative behavior]. Tomsk, Tomsk State University Publ., 2009. 240 p.

22. Syrtsova A., Sokolova E. T., Mitina O. V. Modification of the Zimbardo Time Perspective Inventory. Psikhologicheskii zhurnal, 2008, V. 29, no. 3, pp. 101-109 (in Russian).

23. Sopov V. F., Karpushina L. V. Morphological test of life values. Prikladnaya psikhologiya - Applied Psychology, 2001, no. 4, pp. 9-30 (in Russian).

24. Vasserman L. I., Eryshev O. F., Klubova E. B. et al. Psikhologicheskaya diagnostika indeksa zhiznennogo stilya [Psychological diagnostics of the life style index]. St. Petersburg, V. M. Bekhterev National Research Medical Center for Psychiatry and Neurology, 2005. 54 p. Available at: http://bekhterev.ru/ content/42/2005 dilifestyle.pdf (Accessed 02 December 2018).

25. Kryukova T. L., Kuftyak E. V. Ways of coping questionnaire (WCQ technique modification). Zhurnal prakticheskogo psikhologa - Journal of the Practical Psychologist, 2007, no. 3, pp. 93-112 (in Russian).

26. Lepeshinskii N. N. Modification of Ryff's Scales of Psychological Well-Being. Psikhologicheskii zhurnal, 2007, no. 3, pp. 24-37 (in Russian). Available at: http://media.miu.by/files/store/items/pj/15/pj 152007 3.pdf (Accessed 02 December 2018).

27. Gozman L. Ya., Kroz M. V., Latinskaya M. V. Samoaktualizatsionnyi test [Selfactualization test]. Moscow, Rossiiskoe pedagogicheskoe agentstvo Publ., $1995.43 \mathrm{p}$.

28. Borozdina L. V., Spiridonova I. A. Age-related changes in a subject's time perspective: Part I: Formal parameters. Psikhologicheskii zhurnal, 1998, V. 19, no. 2, pp. 40-50 (in Russian).

29. Anan'ev B. G. Chelovek kak predmet poznaniya [Man as an object of cognition]. St. Petersburg, Piter Publ., 2001. 288 p.

30. Rubinshtein S. L. Bytie i soznanie. Chelovek i mir [Being and consciousness. Man and the world]. St. Petersburg, Piter Publ., 2003. 512 p. 
31. Kovalev V. I. Features of subjective life time regulation. In: Vremya deyatel'nosti lichnosti [Individuals' time of activity]. Chernivtsy, ChSU Publ., 1991, pp. 67-75.

32. Golovakha E. I., Kronik A. A. Psikhologicheskoe vremya lichnosti [Individuals' psychological time]. Moscow, Smysl Publ., 2008. 267 p.

33. Gusel'tseva M. S. Psychology and history: Changing the types of rationality. Voprosy psikhologii, 2011, no. 2, pp. 13-24 (in Russian).

34. Znakov V.V. Psychology of human existence as a direction of the development of a subject's psychology. Psikhologicheskii zhurnal, 2008, V. 29, no. 2, pp. 69-77 (in Russian).

35. Leont'ev D. A. Non-classical vector in modern psychology. Postneklassicheskaya psikhologiya. Sotsial'nyi konstruktsionizm i narrativnyi podkhod-Postmodern psychology. Social constructivism and narrative approach, 2005, no. 1 (2), pp. 51-71 (in Russian).

36. Cottle T. J. Perceiving time: A psychological investigation with men and women. N. Y., John Wiley and Sons Ltd, 1976. 284 p. 